\title{
EMPREGADAS DOMÉSTICAS NEGRAS NO CENÁRIO DA PANDEMIA: ASPECTOS SOBRE A VULNERABILIDADE
}

\section{BLACK HOUSEKEEPERS ON THE PANDEMIC: ASPECTS ON VULNERABILITY}

Isabella Duarte*

Resumo: 0 trabalho em questão busca refletir sobre o impacto da pandemia do COVID-19 em relação às trabalhadoras domésticas. Através de uma análise teórica embasada em pesquisadoras como: Sonia Maria Giacomini, Kimberlé W. Crenshaw, Jurema Brites e Lélia Gonzales, é possível analisar como o contexto histórico e social influenciam diretamente na atual dinâmica trabalhista. O racismo estrutural em conjunto com a interseccionalidade faz com que o perfil da profissão seja majoritariamente de mulheres negras e oriundas de famílias com baixa renda. No momento presente, devido a não observância das recomendações provenientes da Organização Mundial da Saúde em conjunto com a precarização do serviço doméstico, essas mulheres precisam colocar a si mesmas e as suas famílias em risco de vida, sob pena da perca de emprego em tempos de crise. Além disso, por meio de casos concretos evidencia-se a falta de direitos para com essa parcela vulnerável da população brasileira. Portanto, visando ressaltar a responsabilidade do Estado, se destaca uma relação entre a omissão estatal devido à falta de políticas públicas e a fiscalização inadequada do serviço. É nesse contexto que o estudo salienta uma violência velada quanto a essas mulheres, uma vez que o Estado Democrático de Direito deveria guiar os seus preceitos através da dignidade humana.

Palavras-chave: Mulheres Negras. Empregadas Domésticas. Desigualdade. Interseccionalidade. Direitos Humanos.

\begin{abstract}
This work aims to reflect on the impact of the COVID-19 pandemic related to domestic workers. Through a theoretical analysis based on researchers such as: Sonia Maria Giacomini, Kimberlé W. Crenshaw, Jurema Brites and Lélia Gonzales, it is possible to analyze how historical and social context directly influences the current labor dynamics. Structural racism along with intersectionality results at the profile of the profession being mainly of black women and from low-income background. At the present moment, due to the non-observance of the recommendations coming from the World Health Organization together with the precarisation of domestic service, these women need to put themselves and their families at risk of life, under penalty of losing their jobs in times of crisis. Therefore, through cases analysis, the lack of rights to this vulnerable portion of the Brazilian population is evident. In order to emphasize the State responsibility, showing there is a relation between state omission due to lack of public policies and inspection of the service. It is in this context that this study highlights veiled violence towards these women, since the Democratic Rule of Law should guide its precepts through human dignity.
\end{abstract}

\footnotetext{
* Graduanda em Direito pela Universidade Estadual de Londrina (UEL). E-mail: isabella.duart@hotmail.com
} 
NO CENÁRIO DA PANDEMIA....

Keywords: Black Women. Housekeepers. Inequality. Intersectionality. Human Rights.

Recebido em: 30/09/2020. Aceito em: 26/10/2020.

\section{INTRODUÇÃO}


O trabalho doméstico no Brasil sempre foi extremamente requisitado. Porém, em uma análise mais profunda, evidencia a desigualdade social velada e enraizada existente no cotidiano brasileiro. Com o Estado Democrático de Direito tendo como fonte os Direitos Humanos, reformas institucionais foram feitas para que esses empregados tivessem seus direitos e deveres assegurados legalmente, como a Emenda Constitucional no 72, de 2013 (BRASIL, 2013), que estendeu os direitos trabalhistas garantidos na Consolidação das Leis do Trabalho (CLT) aos pertencentes à categoria de serviço e, posteriormente, estendida a Lei Complementar no 150 , de 2015, sancionada pela Presidente Dilma Rousseff (BRASIL, 2015). Entretanto, uma grande indignação deve-se ao fato do Estado reconhecer esses trabalhadores domésticos apenas recentemente e com forte opinião contrária da população brasileira, a qual não os enxergam como empregados dignos de direitos mínimos. Além disso, dados do Instituto Brasileiro de Geografia e Estatística (IBGE) comprovam que a informalidade no setor continuou mesmo após a regulamentação da Lei Complementar no 150: enquanto o índice percentual de trabalhadores domésticos sem carteira de trabalho assinada no primeiro trimestre de 2015 foi de $68,04 \%$, no mesmo período em 2020 o índice chegou a 72,53\%. Isso ressalta que a desigualdade é sempre um peso quando falamos sobre trabalhos considerados como de segunda categoria.

Com os Direitos Humanos zelando por uma condição de vida minimamente digna - sem distinção de raça, cor, sexo, língua, religião ou qualquer outro fator externo -, a grave violação à dignidade humana, perante o cenário atual, no que diz respeito aos trabalhadores domésticos no Brasil, é uma atrocidade. Segundo um estudo divulgado em novembro de 2019 pelo Instituto de Pesquisa Econômica Aplicada (Ipea), essa função há muito tempo possui um perfil bem elaborado, o qual é feminino, negro e pobre. Desse modo, é impossível debater sobre as condições dessas mulheres sem relacionar com o racismo enraizado na sociedade.

Diante do contexto escravocrata do país, é coerente associar as antigas relações de poder com o patriarcado. Sendo a camada mais oprimida em um quadro social, o papel da mulher preta escravizada foi invisibilizado de muitas maneiras: em suas lutas, resistências e desempenhos. Hoje, 132 anos após o fim da escravidão no Brasil, pouca coisa mudou. De fato, o trabalho doméstico é uma continuação dos parâmetros 
escravagistas dentro da elite brasileira. Requisitar os serviços de uma empregada doméstica é um luxo considerável perante o corpo social do país. Consequentemente, a mulher preta continua estagnada em empregos informais, principalmente no setor doméstico, pois segue sendo a camada menos privilegiada na sociedade. Porém, também é sabido que toda forma de trabalho é digna, contanto que tenha o devido reconhecimento legal para segurança dessas trabalhadoras.

Um dos maiores impasses dessa forma de serviço ocorre quando os empregadores desviam das suas obrigações para com as empregadas. Muitos ainda não as respeitam e usam da boa-fé para realizarem acordos verbais sem nenhuma garantia de cumprimento. Com o advento da pandemia mundial, se tornou possível observar a enorme violação da dignidade humana com essa classe trabalhadora através da insegurança em relação aos direitos trabalhistas. Os empecilhos sanitários causaram a demissão de milhões de pessoas no Brasil; entretanto, o setor doméstico se manteve consideravelmente resistente.

Mesmo com a Lei Federal no 13.979, de 6 de fevereiro de 2020 (BRASIL, 2020), informando quais serviços seriam considerados essenciais durante a pandemia, de acordo com a Confederação Nacional dos Trabalhadores no Comércio e Serviço, o prefeito de Bélem foi contra o regulamento e anunciou que as empregadas domésticas entrariam na categoria "essencial" durante o período de isolamento total da cidade, conhecido como lockdown (LACERDA, 2020). Com isso, muitas dessas empregadas se viram obrigadas a cumprir a função que lhes foi imposta, colocando de lado não apenas a própria saúde física e mental, mas também de seus familiares, pois a solução encontrada foi deixar as suas residências e começar a morar no local de serviço, caso contrário, perderiam os seus empregos.

A proposta do presente trabalho é evidenciar, através de uma metodologia histórica explicativa, a violação dos Direitos Humanos por meio de uma soma de fatores sociais, o que faz com que essas mulheres continuem vivendo na subalternidade e esse fator se intensifique durante o atual momento. No Brasil, o serviço doméstico é extremamente desvalorizado, mas aqueles que o usufruem possuem a maior porcentagem de riqueza. Durante o período da pandemia, os contrastes sociais enraizados no cotidiano foram colocados à luz do conhecimento brasileiro e precisam ser devidamente analisados. 


\section{O TRIABALHO DOMÉSTICO COMO CONTINUAÇÃO DO PERÍODO COLONIAL}

Sendo o último país a abolir completamente a escravidão, o Brasil utilizou da mão de obra escrava por mais de três séculos, fazendo com que o tráfico negreiro fosse considerado o maior negócio do mundo até o início do século XIX (LAURENTINO, 2019). A dinâmica do tráfico negreiro de diversos povos africanos para o Brasil Colônia comprova a quantidade de trabalho árduo que existia no país. $O$ perigo constante norteava o cotidiano desses escravizados; trabalho forçado exaustivo e com risco de vida, situação insalubre de sobrevivência e castigos físicos perante fugas ou subversões de valores eram uma rotina que impunha desde crianças, mulheres e idosos ao trabalho forçado sem considerar os seus direitos civis e a sua dignidade humana. O motivo decorre do fato deles não serem vistos como seres dignos de direitos, mas, sim, como bens semoventes, isto é, uma coisa que tem em sua natureza a locomoção, mas pertence a outrem. Não sente, não pensa, não existe em um plano social, apenas serve aquele que o detém. As mazelas citadas eram erroneamente justificadas pelos pensamentos ideológicos da época, os quais são muito bem representados pelo jesuíta italiano André João Antonil (1982, p. 89): "os escravos são as mãos e os pés do senhor do engenho". Perante os privilegiados da época, impossível seria o Brasil colonial sem um povo sendo explorado.

Com um número descomunal de serviços a serem realizados, as funções eram divididas, o que - por um mero deleite da elite - se exigiu uma parcela de "escravos de serviço" abrangendo a Casa Grande. Dentre a maioria desses escravizados que eram forçados ao trabalho dentro do núcleo familiar, têm-se, em regra, mulheres. A antropóloga Sonia Maria Giacomini, analisa o papel da mulher negra durante o período escravocrata e ressalta a sua função social como trabalhadora, mas também converge a relação entre senhor/escrava e a função sexual que a designavam.

Pois a negra é coisa, pau para toda obra, objeto de compra e venda em razão de sua condição de escrava. Mas é objeto sexual, ama de leite, saco de pancada das sinhazinhas, porque além de escrava é mulher. Evidentemente essa maneira de viver a chamada 'condição feminina' não se dá fora da condição de classe (...) e mesmo de cor. (GIACOMINI, 1988, p. 87-88).

O papel social como trabalhadora era devido à imposição ao mesmo trabalho 
árduo que os homens realizavam. Entretanto, ocorre a designação de funções através da evidência do estereótipo feminino referente ao papel de cuidadora e maternal. As escravizadas, conhecidas como mucamas, realizavam todas as tarefas domésticas, incluindo a dura função de ama de leite para os filhos de seus patrões. Porém, para isso acontecer, a mulher precisava engravidar, o que abrange a função sexual da escravizada.

Quando se estuda a relação senhor/escrava, não é obstante o fato das mulheres negras serem estupradas constantemente durante o período de escravidão. Eram comuns anúncios em jornais da época, como "O Correio Paulistano", onde o corpo da escravizada que estava sendo vendida era detalhadamente especificado. Dentro desse cenário próximo ao convívio familiar, a hierarquia não era menor e os perigos aumentavam em conjunto com as torturas físicas e psicológicas. Todos os lugares sociais eram devidamente relembrados, como forma de amedrontar e evitar revoltas. Desse modo, subordinadas ao sofrimento e humilhação desde quando retiradas do seu continente, essas mulheres cuidavam da casa e dos filhos alheios provendo conforto e saúde, ao mesmo tempo em que eram submetidas a condições extremas de violência. Durante a história, foram invisibilizadas, porém é importante salientar que por muito tempo a mulher negra foi vista apenas como um objeto que está a disposição do servir. Hoje, 132 anos após o fim da escravidão, o reflexo disso vem à tona.

\section{O PERFIL DAS DOMÉSTICAS}

O trabalho doméstico, apesar de enfraquecido em outros lugares do mundo, sempre foi muito marcante no cotidiano brasileiro. Funções que aliviam o peso do cuidado com o Lar, como faxineiras, jardineiros, babás e cuidadoras, atraem diversas famílias com as devidas condições financeiras para contratar esse tipo de luxo. Considerando que toda forma de trabalho é digna, não há problema em estabelecer uma relação de empregado e empregador para com esses prestadores de serviço. Entretanto, a rotina do trabalhador doméstico muitas vezes ultrapassa a esfera laboral e reflete diretamente nas âmbito pessoal.

Em uma primeira análise, é de extrema importância entender quem são as pessoas que compõe o trabalho doméstico. Segundo um estudo divulgado por Pinheiro 
e outros (2019), dentre um total de 6,2 milhões de trabalhadores domésticos, 5,7 milhões eram mulheres, entretanto, 3,9 milhões eram negras, o que oficializa um perfil para esse tipo de atividade. De acordo com o Dossiê Mulheres Negras (MARCONDES et al, 2013), em regra, essas mulheres são pretas, com baixa escolaridade e vindas de famílias pobres. O que acaba fazendo com que seja inquestionável a interferência da raça, gênero e classe no âmbito das relações trabalhistas.

O mercado de trabalho, por sua vez, representa o microcosmo da sociedade. No entanto, sociedade esta que não é equilibrada, o que agrava e ressalta algumas desigualdades. Em uma pirâmide social, temos: homens brancos, mulheres brancas, homens negros e mulheres negras. É uma constante o fato dos cargos de chefia serem preenchidos por pessoas brancas, enquanto os trabalhos informais são majoritariamente marcados por pessoas negras. Além disso, os homens brancos são os maiores beneficiados economicamente, sendo a mulher branca a segunda privilegiada em relação ao salário; enquanto isso, homens e mulheres negras continuam recebendo menos do que realmente merecem, muitas vezes realizando exatamente a mesma função da classe que é colocada acima deles. Com isso, tem-se a mulher negra sendo oprimida estruturalmente, quase como uma punição por não preencher os devidos requisitos de uma pessoa que se adeque na sociedade.

Em uma análise mais profunda, vale salientar o peso da interseccionalidade no mundo atual. $\mathrm{O}$ conceito teorizado pela primeira vez em um texto da advogada e professora de Direito Kimberle Crenshaw (1989) diz respeito ao entrelaçamento entre eixos de subordinação, isto é, quanto mais fatores acumulativos e que não são vistos positivamente pela sociedade, mais oprimido será o cidadão. No caso em questão, temos como fatores determinantes: raça, gênero e classe social. Com isso, torna-se evidente que viver em uma sociedade que representa o patriarcal, o racista e o elitista - enquanto se representa o feminino, o negro e o pobre - é viver diariamente com uma penalidade tripla. Considerar a interseccionalidade é validar a existência das mulheres negras e viabilizar a possibilidade de políticas públicas com o enfoque de promover a igualdade de gênero, raça e classe. Estados que não observam relevância em levar em consideração essas mulheres, são os mesmos que legitimam o racismo e o sexismo institucional atual, onde as ofertas de emprego são baixas igualmente aos salários (pelo fato das canditadas serem mulheres e negras) e, muitas vezes, a informalidade acaba 
sendo a única opção.

Tabela 1 - Desigualdades Sociais por Cor ou Raça no Brasil 40 trimestre de 2019

\begin{tabular}{c|c}
\hline Categoria & Quantidade (em \%) \\
\hline Homens Brancos & 34,4 \\
Mulheres Brancas & 34,7 \\
Homens Negros & 46,9 \\
Mulheres Negras & 47,8
\end{tabular}

Fonte: Pesquisa Nacional por Amostra de Domicílios Contínua, 40 trimestre de 2019 (IBGE, 2019a); IBGE (2019b); Pinheiro (2019).

É importante considerar que, dentro do estereótipo de que o feminino é designado às funções do espaço privado, as mulheres negras sempre ocuparam os espaços públicos. Tendo em mente uma análise histórica, as negras forras cumpriram um importante papel nesse aspecto da vida econômica e social no período colonial. Movimentavam o varejo e comércio ambulante, eram parte da força de trabalho e, consequentemente, ajudaram na urbanização de algumas localidades (RODRIGUES, 2005). Hoje em dia esse reflexo é observado - conforme evidenciado na tabela através do fato das mulheres negras ocuparem mais de $10 \%$ dos trabalhos informais do que as mulheres brancas, pois isso faz com que elas transitem o espaço público e se integram a ele. Uma mulher negra e com baixa renda que vive em uma capital provavelmente usa mais de um (1) transporte público cotidianamente para ir trabalhar, uma vez que a maioria é chefe de família. Assim, o trabalho doméstico informal, para uma mulher negra, é a união da ocupação do espaço público e da prestação de serviço no âmbito privado, uma dualidade que nem sempre é positiva.

\section{DO PRECONCEITO A FALTA DE DIREITOS}

Conforme o exposto, é correto dizer que a desigualdade social no Brasil tem como base o seu passado colonial, o qual é extremamente recente. Bebendo na fonte do racismo estrutural, isto é, uma sociedade pautada em uma estrutura com sistemas institucionais que oprimem determinados grupos sociais e étnicos em detrimento de 
outros, a relação entre dominador e dominado foi fortalecida e, a partir disso, criaramse espaços de segregação.

Dentre todos os países do mundo, o Brasil assume a liderança no ranking com o maior número de empregadas domésticas, segundo a Organização Internacional do Trabalho (OIT). A maior perplexidade perante esse recorde é o fato de ser um trabalho com alta demanda ao mesmo tento em que possui um lugar fixo entre os serviços com piores salários. Entretanto, cuidar do Lar, ao contrário do que muito se pensa, é uma função exaustiva física e mentalmente.

O cansaço físico é um fato inevitável para com as domésticas, principalmente com as de mais idade. Lavar, passar, cozinhar, cuidar dos vulneráveis e, ainda, precisar lidar com o preconceito velado dentro do núcleo familiar alheio. $O$ esgotamento mental provém exatamente disso. Na maioria dos casos, o trabalho doméstico não é esporádico, mas envolve anos de compromisso com uma mesma família. Em seu artigo, a antropóloga Jurema Brites (2007) analisou o afeto que norteia essa relação profissional; é de praxe que os adultos mantenham uma relação de distanciamento e desinteresse na vida da trabalhadora, no caso das crianças, observa-se o oposto. A professora afirma que as crianças aumentam a sua perspectiva de mundo devido ao contato com aquelas que as zelam durante o dia. Diversos são os casos em que os patrões precisam sair de casa e deixam os mais vulneráveis sob os cuidados da faxineira, o que não faz parte das suas obrigações de prestação de serviço. Com isso, as crianças se sentem mais confortáveis e, consequentemente, mais próximas dessa mulher, não obstante, o inverso também ocorre, pois ela não se sente desconfortável em se relacionar com, provavelmente, a única pessoa da família que Ihe oferece atenção e respeito. Brites (2007, p. 98) comprova esse forte vínculo afetuoso através da reflexão "De fato, muitas vezes, o motivo para uma empregada agüentar um serviço mal pago é a dificuldade em se separar das crianças das quais toma conta". A partir disso, é possível observar a sobrecarga com as trabalhadoras e a dificuldade de se desvincular de um emprego insuportável, o qual as agride de diversas maneiras.

Ademais, é importante pontuar que elas precisam enfrentar o grave preconceito diário. No cotidiano brasileiro é comum que essas mulheres sejam humilhadas em tom jocoso pelo núcleo familiar que as contrata. Isso acontece, principalmente, pela falta de consciência de classe. A elite do país não se enxerga na camada popular, mesmo 
que estatisticamente seja mais fácil ela regredir do que progredir em uma pirâmide social, acredita que o mundo externo não Ihe diz respeito. Com isso, usam de uma falácia popular: "nós a consideramos como se fosse da família". Porém, ao mesmo tempo em que esse grupo privilegiado superficialmente acolhe, também as discrimina repetidamente. O preconceito não precisa ser explícito, mas acontece de diversos modos, dentre eles: são proibidas de usar o banheiro, precisam levar a sua comida e os próprios talheres, são constantemente humilhadas em tom de brincadeira, devem usar uniforme específico quando em público. Tudo isso engloba uma estratégia para fazer com que a doméstica se lembre de que ela não pertence àquele ciclo social. Nesse viés, a antropóloga brasileira Lélia Gonzalez, no seu livro "Lugar de Negro" (1982), pontua o conceito da "divisão racial do espaço" e elude a questão de como a organização do espaço urbano reflete incisivamente na dinâmica social. Segundo a autora, existe um lugar natural (sic) das pessoas brancas e pessoas pretas; enquanto o primeiro grupo pertence aos melhores pontos da cidade e com elevado padrão de vida, o segundo vive em situação de miséria (GONZALEZ; HASENBALG, 1982). Uma empregada doméstica transita entre esses dois lugares naturais todos os dias e absorve os reflexos dessa segregação. O desconforto é proposital e converge com o medo. Em vista disso, é de imensa preocupação o fato de esse serviço ser o mais requerido enquanto, simultaneamente, é o que menos garante direitos para uma condição de vida minimamente digna.

Essa categoria de serviço carece em assistência por parte do Estado, mas quem agrava a situação devido à falta de interesse em conceder direitos são os próprios empregadores. O Brasil é um país que esbanja discriminação em seu tecido social e agrega, sistematicamente, o preconceito considerado "velado". Dessa forma, vale salientar que mesmo após mais de um século de abolição da escravidão, o trabalho doméstico foi regulamentado há menos de uma década através da, popularmente conhecida, "PEC das domésticas".

Todavia, o sistema hoje em vigor, que permite a existência de trabalhadores de segunda categoria, é uma verdadeira nódoa na Constituição democrática de 1988 e deve ser extinto, pois não há justificativa ética para que possamos conviver por mais tempos com essa iniquidade. (BEZERRA, 2010, p.2).

A Emenda Constitucional no 72, de 2013 (BRASIL, 2013) em conjunto com a Lei Complementar 150/2015 (BRASIL, 2015), de fato reconheceu a importância dessas 
trabalhadoras para o país e pretendeu estabelecer igualdade através dos direitos trabalhistas. Juridicamente, essa categoria obteve garantias mínimas para um trabalho digno. Entretanto, atualmente é possível observar que tal medida não funcionou em sua integridade, pois o número de trabalhadoras registradas é ínfimo quando comparado com o todo. Segundo o Instituto Brasileiro de Geografia e Estatística (IBGE), em 2018, o número de domésticas era de 6.3 milhões, mas apenas 1.9 milhões tinham carteira assinada. Portanto, mesmo quando os direitos são garantidos por lei, a sociedade brasileira, principalmente a elite, se mostra resistente e não valoriza as mulheres que todos os dias zelam pela família alheia.

\section{O TRABALHO DOMÉSTICO NO CENÁRIO DA PANDEMIA}

Uma das maiores premissas em uma sociedade é esforçar-se em conjunto para manter a ordem. Entretanto, historicamente pode-se observar que fatores externos tendem a desregular essa plenitude na harmonia. No caso do trabalho doméstico, a pandemia mundial referente ao COVID-19 evidenciou profundo descaso em relação às pessoas que realizam esse tipo de serviço.

Segundo a Organização Internacional do Trabalho (2011), o trabalho digno se configura como aquele que abrange objetivos simples para garantir a dignidade da pessoa humana, entre eles, a remuneração adequada, a igualdade, proteção, o desenvolvimento e liberdade. Além disso, pelo fato da Constituição Federal de 1988 ter respeitado e considerado os Direitos Humanos, um rol de Direitos Sociais foram garantidos na Carta Magna, o qual - inclusive - assegura a dignidade dos trabalhadores domésticos. Contudo, o problema enraizado desde o primórdio da criação do Estado Democrático de Direito, no Brasil, é que os administradores se esquecem de adotar uma postura ativa em relação aos Direitos Sociais e, por conta disso, o país ainda se encontra com um dos piores índices de desigualdade social.

Através dessa omissão estatal, torna-se possível perceber o motivo pelo qual, mesmo após toda a discussão e regulamentação da Lei Complementar no 150/2015 (BRASIL, 2015), a informalidade ter continuado presente. Em tempos de pandemia, a precariedade sanitária da condição de trabalho dessas mulheres, se mostra uma grave violação dos Direitos Humanos. 
Enquanto alguns Municípios adotavam medidas de proteção contra a proliferação inadequada da doença, outros optaram por ir contra as recomendações oficiais da Organização Mundial de Saúde (OMS) e considerar o trabalho doméstico como essencial. Assim sendo, as mulheres desse setor precisaram decidir entre: considerariam abandonar o emprego (em um país onde o índice de desempregados é alarmante) em prol da saúde ou enfrentar os riscos para conseguir colocar comida na mesa. Novamente considerando os fatores da interseccionalidade, as mulheres negras, que se encontram na base da pirâmide social, foram obrigadas a aceitar os novos termos de serviço e voltar ao trabalho. Esse é o problema da informalidade.

De acordo com o Instituto Locomotiva, desde o começo da pandemia, 39\% das diaristas foram dispensadas sem pagamento. Em suma, a categoria mais vulnerável da sociedade está sendo coagida pelos seus empregadores sob pena de demissão. Sem emprego e auxílio governamental, a sobrevivência se torna um desafio. A solução encontrada, em tempos de isolamento social, foi permitir que as trabalhadoras fizessem do local de trabalho uma residência. Assim, mulheres negras estão precisando desconsiderar o seu próprio Lar - não apenas a residência, mas também a família e as relações sociais que a norteiam - para servir o outro. No entanto, tirar a rede de apoio dessas mulheres é um grande problema, considerando que a solidão e a falta de afeto é uma pauta temática do grupo em questão.

Apesar do maior vínculo consequente dessa nova jornada de trabalho, os abusos físicos e mentais exacerbam-se. Viver no local de emprego, sem qualquer tipo de regulamentação, por vezes extrapola os limites da carga horária diária. Além disso, precisam lidar com o desrespeito e descaso constante. Descaso este que, em tempos de quarentena, aconteceu de modo descarado, pois a elite brasileira não consegue, ao menos, considerar a humanidade nas pessoas que Ihes prestam serviço dentro de suas casas, isto é, não conseguem se enxergar no outro.

Com isso, atualmente, tem-se dois casos marcantes que ocorreram no país. 0 primeiro refere-se à doméstica Cleonice Gonçalves, 63 anos, morta após ter sido contaminada com COVID-19 pelos chefes recém-chegados da Itália. Não obstante, o segundo diz respeito ao caso investigado envolvendo a morte do menino Miguel Otávio Santana da Silva, 5 anos, filho da empregada doméstica Mirtes Renata Santana. Examinando as situações expostas, respectivamente, se tem a carência de zelo em 
relação a essa classe trabalhadora, uma vez que os empregadores sabiam do risco de contágio e mesmo assim optaram pela obrigatoriedade da prestação de serviço; além disso, se observa um caso peculiar onde as relações raciais acabaram por sobressair o direito à vida, posto que um adulto branco e rico não se enxergou como semelhante à uma criança preta e com baixa renda, ou seja, é possível verificar uma imensa divergência de classes onde tem-se o valor da vida comum reduzido perante um grupo privilegiado socialmente. Ambos ressaltam o desdém para com essas trabalhadoras, as quais todos os dias arriscam a própria vida para atender o núcleo familiar alheio.

\section{ESTADO DEMOCRÁTICO DE DIREITO PARA QUEM?}

Apesar de uma base constitucional fortemente elaborada, o Brasil ainda contém um alto índice de desigualdade social. Tal fator não deveria ser ignorado pelos seus representantes, pois engloba vidas, isto é, pessoas no máximo da sua identidade. 0 país que não se preocupa com a sua população mais vulnerável é o mesmo que legitima mortes todos os dias.

A Constituição Federal de 1988 (BRASIL, [2020]) idealizou o progresso na nação brasileira. Considerado um Estado Democrático de Direito e visando o Bem-Estar Social dos seus cidadãos, colocou em sua Carta Magna todos os requisitos para a criação de medidas mais igualitárias. Todavia, no geral, foram apenas promessas. Para garantir a efetividade de um Estado que se preocupa com a sociedade, deve-se, primeiramente, considerar os fatores opressores desta. Somente é possível abolir práticas discriminatórias quando elas são consideradas existentes e merecedoras de devida atenção governamental. A partir disso, torna-se mais fácil repelir as mazelas que assombram um povo inteiro. Vale ressaltar que os problemas que envolvem grupos considerados minorias e que são diariamente oprimidos transcendem a Esfera Privada e atingem a coletividade, isto é, dizem respeito às matérias do Estado.

Uma vez que os Direitos Sociais são garantidos na Constituição Federal, qual seria o motivo plausível para não efetivá-los? Problemas de Ordem Pública precisam ser resolvidos através dos instrumentos jurídicos, os quais, quando coerentes com a causa, ajudam a combater essas adversidades. Ainda, a Declaração Universal dos Direitos Humanos (1948) estreou como verdade absoluta que "o reconhecimento da dignidade 
inerente a todos os membros da família humana e de seus direitos iguais e inalienáveis é o fundamento da liberdade, da justiça e da paz no mundo" e, em vista disso, o legislador foi precavido ao inserir no artigo $1^{\circ}$ da Constituição Federal, entre os seus fundamentos primordiais, a dignidade da pessoa humana. Porém, a falta de delimitação sobre quais seriam os atos que a ferem, fez com que pouco se observasse quanto à garantia e real efetivação desse fator no país, mesmo tendo mais de três décadas da sua elaboração. Quando as normas trabalhistas são observadas, nesse mesmo viés, o problema atinge proporções maiores.

A humanidade é demarcada pela visão do trabalho sendo quase um sinônimo de dignidade e, a partir disso, surge a ideia de que todo trabalho é digno. Entretanto, o trabalho doméstico ainda é visto como inferior perante a sociedade, pois pressupõe a falta de oportunidade e escolha para realizá-lo. De acordo com a Convenção ( $n^{\circ} 189$ ) e da Recomendação (n 201) sobre as Trabalhadoras e os Trabalhadores Domésticos, realizadas pelo OIT em 2011 (ORGANIZAÇÃO INTERNACIONAL DO TRABALHO, 2011), e onde o Brasil foi membro ativo, a proteção dessas trabalhadoras em relação à jornada de trabalho, condições de emprego decente, liberdade de escolha sobre o domicílio, remuneração mínima, condições adequadas de acomodação e alimentação, entre muitos outros, são requisitos mínimos que deveriam ser assegurados. Contudo, devido ao seu passado escravocrata, o Brasil ainda possui esses aspectos mais exaltados, pois configuraram o senso comum de que qualquer função que era realizada por escravizados, ainda hoje, não é digna de consideração. Desse modo, a contínua ascensão da informalidade no setor acaba sendo regra.

Portanto, através da omissão, o Estado não fiscaliza as relações laborais presentes nesses núcleos familiares. Além disso, com ideologias de governos liberais em pauta, a discussão sobre a flexibilização das normas trabalhistas voltam aos debates, o que coloca em situação de risco os direitos dos trabalhadores que foram duramente conquistados ano após ano. Porém, o que não se pondera é que garantir a mínima condição de trabalho digno para uma pessoa considerada vulnerável perante a sociedade é, como o próprio nome afirma, o mínimo a ser feito.

\section{CONSIDERAÇÕES FINAIS}


A dignidade vai além de como ela é interpretada na sociedade, uma vez que prova ao ser humano a sua força e importância como ser único, individual. Devido a sua força nuclear e irradiadora, inumeráveis áreas da sociedade são influenciadas pela dignidade da pessoa humana; influência esta que deveria ser garantida por aqueles de maior poder. A barbárie atual não causa espanto por ainda acontecer, mas, sim, pela sociedade já ter consciência de que esses direitos devem ser respeitados e, mesmo assim, continuar os agredindo cada vez mais.

O vínculo entre a violência velada e a omissão dos governantes fere a base da pirâmide social, mas também possui reflexo como um todo. É indubitável que o passado colonial do Brasil ainda espelha o comportamento dos cidadãos. O racismo é uma mazela estrutural e demasiadamente enraizada. Porém, o trabalho doméstico não deveria ser considerado degradante igualmente ao fato de que aquele que o realiza não deveria ter a sua dignidade apagada.

Como exposto, são as mulheres negras as maiores prejudicadas nesse contexto de informalidade. Colocadas como subalternas, devido à interseccionalidade, precisam enfrentar uma rotina diária de preconceitos e não oportunidades por simplesmente ser quem são, o que evidencia a brutalidade e falta de apreço da sociedade com essas mulheres. Apesar disso, elas são válidas e precisam ser protegidas, mas não apenas no cenário da pandemia. Em tempos de crise, a sociedade perde a sua característica de estabilidade. Assim, evidenciando problemas que não foram sanados durante séculos. O que nota-se atualmente é apenas uma continuação de um fato problemático cujo país não deu a devida atenção, por diversas vezes, ignorando ou camuflando com medidas temporárias.

Em conclusão, a falta de políticas públicas efetivas é uma grave violação quando se busca a proteção dessa classe trabalhadora. Assim, a mudança começa a partir do trabalho do Estado em conjunto aos seus Órgãos Competentes. Por mais que a Lei Complementar 150/2015 seja recente, é de suma importância a regulamentação e fiscalização do que a compõe. As empregadas domésticas precisam ser legalmente amparadas, pois quanto maior a abrangência de direitos, maiores as chances de retirar não apenas essa classe trabalhadora da condição de pobreza e vulnerabilidade, mas também as futuras gerações. Dessa maneira, é importante lembrar que a tendência de 
flexibilizar as leis trabalhistas geraria frutos negativos em relação aos trabalhadores, uma vez que o mercado de trabalho nada mais é do que a constante luta de poder por aquele que o detém e aquele que oferece a força de trabalho. Logo, o mais forte tende a se sobressair quanto à regulamentação dos benefícios, ou seja, mitigando direitos mínimos.

Por fim, o caminho para a construção de uma sociedade igualitária é árduo e conflitante. Não obstante, uma vez guiado pelos princípios ideais, conseguiria reestruturar uma nova ideologia na nação e, possivelmente, ser influenciador para outras tantas. O Estado Democrático de Direito precisa ter condições suficientes para assegurar aqueles que acreditam na sua real efetividade, destarte, restaurando a simetria, unidade e integridade ideológica daquilo que o regula. Apenas assim essas trabalhadoras conseguirão o devido respeito legal que merecem. Caso contrário, a posição de subalternidade e a falta de direitos mínimos permanecerão enraizadas na sociedade brasileira.

\section{REFERÊNCIAS}

ANTONIL, André João. Cultura e opulência do Brasil. Est. Bibliogr. Por Affonso Taunay; notas de Fernando Sales. Belo Horizonte: Itatiaia; São Paulo: EDUSP, 1982.

BEZERRA, Carlos et al. Proposta de Emenda à Constituição Original, no 478 de 2010. [S. /.], 2010. Disponível em:

https://www.camara.leg.br/proposicoesWeb/prop_mostrarintegra;jsessionid=8427422E 78B21D63A1997E1E4B6809BA. proposicoesWebExterno1? codteor $=755258 \&$ filename $=P$ EC+478/2010. Acesso em: 16 set. 2020.

BRASIL. [Constituição (1988)]. Constituição da República Federativa do Brasil de 1988. Brasília, DF: Presidência da República, [2020]. Disponível em: http://www.planalto.gov.br/ccivil_03/constituicao/constituicaocompilado.htm. Acesso em: 24 jun. 2020.

BRASIL. Emenda Constitucional $\mathbf{n}^{\circ}$ 72, de 2 de abril de 2013. Altera a redação do parágrafo único do art. 70 da Constituição Federal para estabelecer a igualdade de direitos trabalhistas entre os trabalhadores domésticos e os demais trabalhadores urbanos e rurais. Brasília, DF: Presidência da República, 2013. Disponível em: http://www.planalto.gov.br/ccivil_03/constituicao/emendas/emc/emc72.htm\#: :text $=$ EMENDA $\% 20$ CONSTITUCIONAL $\% 20 N \% C 2 \% B A \% 2072 \% 2 C \% 20 D E$,demais $\% 20$ traba Ihadores\%20urbanos\%20e\%20rurais. Acesso em: 20 out. 2020.

BRASIL. Lei n⿳0 13.979, de 6 de fevereiro de 2020. Dispõe sobre as medidas para enfrentamento da emergência de saúde pública de importância internacional 
decorrente do coronavírus responsável pelo surto de 2019. Brasília, DF: Presidência da República, 2020. Disponível em: http://www.planalto.gov.br/ccivil_03/_ato20192022/2020/lei/L13979.htm. Acesso em: 20 out. 2020.

BRASIL. Lei complementar $\mathbf{n}^{\circ} \mathbf{1 5 0}$, de $1^{\circ}$ de junho de 2015. Dispõe sobre 0 contrato de trabalho doméstico; altera as Leis no 8.212, de 24 de julho de 1991, no 8.213, de 24 de julho de 1991... Brasília, DF: Câmara dos Deputados, 2015. Disponível em: https://www2.camara.leg.br/legin/fed/leicom/2015/leicomplementar150-1-junho-2015-780907-publicacaooriginal-147120-pl.html. Acesso em: 20 out. 2020.

BRITES, Jurema. Afeto e desigualdade: gênero, geração e classe entre empregadas domésticas e seus empregadores. Cadernos Pagu, Campinas, n. 29, p. 91-109, jul./dez. 2007. Disponível em: https://www.scielo.br/pdf/cpa/n29/a05n29.pdf. Acesso em: 22 out. 2020.

CRENSHAW, Kimberlé W. Demarginalizing the intersection of race and sex: a black feminist critique of antidiscrimination doctrine, feminist theory and antiracist politics. University of Chicago Legal Forum, [S. I.], p. 139-167, 1989.

GIACOMINI, Sonia Maria. Mulher e escrava: uma introdução ao estudo da mulher negra no Brasil. Rio de Janeiro: Vozes, 1988.

GONZALEZ, Lélia; HASENBALG, Carlos. Lugar de Negro. Rio de Janeiro: Editora Marco Zero, 1982.

IBGE. Desigualdades sociais por cor ou raça no Brasil. Rio de Janeiro, $2019 \mathrm{~b}$. Disponível em: https://www.ibge.gov.br/estatisticas/sociais/populacao/25844desigualdades-sociais-por-cor-ou-raca.html?=\&t=publicacoes. Acesso em: 15 set. 2020.

IBGE. Pesquisa Nacional por Amostra de Domicílios Contínua: PNAD Contínua: sobre: 2019 outras formas de trabalho. [S. I.], 2019a. Disponível em: https://www.ibge.gov.br/estatisticas/sociais/trabalho/17270-pnadcontinua.html?edicao=27762\&t=sobre. Acesso em: 14 ago. 2020.

LACERDA, Lorena. Empregos domésticos: serviços "essenciais" ou necessidades "coloniais"?. Confederação Nacional dos Trabalhadores no Comércio e Serviço, 20 maio 2020. Disponível em: http://contracs.org.br/destaque-central/16765/empregosdomesticos-servicos-essenciais-ou-necessidades-coloniais. Acesso em: 20 out. 2020.

LAURENTINO, Gomes. Escravidão: do primeiro leilão de cativos em Portugal à morte de Zumbi dos Palmares. Rio de Janeiro: Globo Livros, 2019.

MARCONDES, Mariana Mazzini et al. (Org.). Dossiê Mulheres Negras: retrato das condições de vida das mulheres negras no Brasil. Brasília, DF: Ipea, 2013. 


\section{sobre Trabalho Decente para as Trabalhadoras e os Trabalhadores}

Domésticos. [S. I: OIT, 2011. Disponível em:

https://www.ilo.org/brasilia/temas/trabalho-domestico/WCMS_169517/lang--

pt/index.htm. Acesso em: 22 out. 2020.

\section{PINHEIRO, Luana et al . Os Desafios do Passado no Trabalho Doméstico do}

Século XXI: reflexões para o caso brasileiro a partir dos dados da PNAD Contínual. Brasília, DF: Ipea, 2019. Disponível em:

https://www.ipea.gov.br/portal/index.php?option=com_content\&view=article\&id=352 31\&Itemid=444. Acesso em: 20 out. 2020.

RODRIGUES, Vilmara Lucia. Negras Senhoras: o universo material das mulheres africanas forras. In: COLÓQUIO DO LAHES, 1., 2005, Juiz de Fora. Anais eletrônicos [...]. Juiz de Fora: UFJF, 2005. Disponível em:

https://www.ufjf.br/lahes/files/2010/03/c1-a69.pdf. Acesso em: 24 out. 2020. 